\title{
Low-Power and Lossy Networks of Wireless Sensor Networks with Protocols Algorithm Comparison
}

\author{
Puput Dani Prasetyo Adi a,b,1,*, Akio Kitagawa ${ }^{\text {b,2 }}$ Abd. rabi' ${ }^{a, 2}$, Nachrowie ${ }^{\mathrm{a}, 4}$, Rahman Arifuddin ${ }^{\mathrm{a}, 5}$ \\ a University of Merdeka Malang, Malang, Indonesia \\ b Kanazawa University, Kanazawa, Japan \\ ${ }^{1}$ puput.danny@unmer.ac.id *; ${ }^{2}$ kitagawa@is.t.kanazawa-u.ac.jp; ${ }^{3}$ arrabik@unmer.ac.id; ${ }^{4}$ nachrowie@unmer.ac.id; \\ ${ }^{5}$ rahman.arifuddin@unmer.ac.id \\ * corresponding author
}

\section{ABSTRACT}

Keywords

WSN

HEED

LEACH

LEACH-TLCH

PEGASIS

RPL

Efficiency

IoT
This research focuses on the energy efficiency needed by sensor nodes in the network architecture i.e, LEACH, HEED, LEACH-TLCH and PEGASIS according to the Routing Protocol Low Power and Lossy Network (RPL) pattern. In this research compared all algorithms based on the number of different sensor nodes. In this research, there is no focus on the type of sensor used but rests on the conclusions of the total results of the Overall energy (Avg Energy) on clustering with the most appropriate networking strategy. In this research, 20, 50 and 100 nodes were tested in the HEED, LEACH, LEACH-TLCH and PEGASIS Algorithms respectively. furthermore, from the results of testing the total Power $(\mathrm{mW})$ sensor obtained from the sum of 4 components of the Power Sensor node, i.e, CPU Power, Power LPM, Power TX (Transmitter) and Power Rx (Receiver), concludes the Power Consumption sensor node is affected by the number of nodes found on the Sensor Node Network Architecture, the lowest Power Consumption is the LEACH Algorithm Protocol with a total of $2,038 \mathrm{~mW}$ at 100 nodes, while the highest Power Consumption is LEACH-TLCH Protocol Algorithm 4,851 mW with 100 nodes followed by PEGASIS with total Consumption $4.31 \mathrm{~mW}$. accordingly the simulation, At the lowest sensor node in this experiment, which is 20 nodes, LEACH produces the lowest total Power of $1.21 \mathrm{~mW}$, while the highest is PEGASIS $1,361 \mathrm{~mW}$. At the number of 50 nodes, the lowest is HEED with a power consumption of $1,558 \mathrm{~mW}$, this result is only 0.046 $\mathrm{mW}$ with the LEACH Algorithm Protocol which is $1,604 \mathrm{~mW}$. Furthermore, by building the right sensor network (WSN) it will support IoT networks with long sensor lifetime.

\section{Introduction}

The current Internet of Things is an inseparable part of human life today. e.g. Health monitoring and health body monitoring, this is an interesting research focus to be developed, one wants to know the pulse and blood pressure levels in running conditions, using devices that are used are very small, light and comfortable in the human body parts. for example in the industrial world, the use of sensors can be used to calculate items that are ready for packing and distribution. All are recorded and displayed on a device in the monitor system section of the company, in central monitoring and monitors wherever they are. In previous research on health monitoring, how to create a sensor node that can monitor Blood Pressure and Patient's pulse [1] [2]The LR-WPANs tool used is the Zigbee module. Zigbee works on a $2.4 \mathrm{GHz}$ frequency and $250 \mathrm{kbps}$ data rate. The essence of the research discussion is on energy efficiency. accordingly, LEACH, HEED, LEACH-TLCH, PEGASIS Algorithm are examples of Wireless Sensor Network network topology that is used to analyze the results of energy efficiency on the Wireless Sensor Network. Testing of the 4 Algorithms is the multi-sensor nodes that handle the clustering system, the more able to provide energy efficiency in the Wireless Sensor Network (WSN) system. furthermore, Equation about energy efficiency will be presented in the next sub-chapter in this paper. In the results of the testing carried out using open sources Contiki Cooja version 2.7 software [3], in research [4] using the TinyOS v1.0 operating system. TinyOS v2.0 and Mantis. the sensor node that handles multi-sensor sender nodes will require a large amount of energy $(\mathrm{mW})$ and this can be shown in the data to be delivered in the chapter result. consequently, that in building a Wireless Sensor Network, more clusters are needed and the fewer cluster members send data to a cluster, consequently this energy efficiency will be increased, pay attention to Figure 1 about Clustering of WSN. 
In Figure 1 there are 3 different conditions in the WSN System, i.e, a, b and c condition. in this case, the best in terms of energy efficiency is c condition, in Figure 1 (a) all sensor nodes are focused on 1 sensor, $\mathrm{N} 2$, and $\mathrm{N} 2$ requires a more of energy to send to $\mathrm{CN}$. This can be proven by simulation software Contiki cooja 2.7 which successfully compares the various algorithm routings tested in the research in this paper. In Fig 1 (b) with the same number of end nodes, but divided into system clustering, what is the difference between Figure 1 (b) and Figure 1 (c) is the number of members in 1 cluster. In Figure 1 (b) the number of members in 1 cluster is more than the number of clustering Figure 1 (b), consequently, the best energy efficiency is in Figure 1 (c) in this case, the sensor node loads to send broken data to all sensor nodes, this good energy equalization occurs at each sensor node. Each sender sensor is given the responsibility of being a cluster head and sending data from a few members in cluster 1 , cluster 2 , etc. on so that the energy in cluster 1 , cluster 2 , etc, on becomes smaller $(\mathrm{mW})$ and not focused on 1 router node sensor. furthermore, This applies to all types of Protocol Algorithm with various forms of algorithms and structures in the Protocol or Network Architecture on IEEE 802.15.4 networks that focus on Low Power Energy sensor nodes.

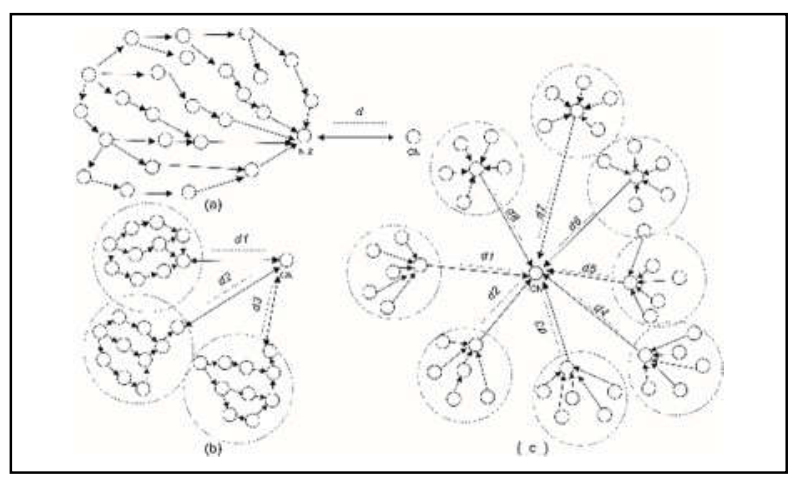

Fig. 1. Energy Efficiency on Clustering of WSN

\section{The Proposed Method/Algorithm}

\subsection{WSN Topology}

Low Energy Adaptive Clustering Hierarchy (LEACH) Protocol is a Wireless Sensor Network (WSN) network architecture that forms clusters with 1 Cluster Head, therefore, each Cluster Head sends packet data to the Base Station / Edge router. accordingly, the LEACH Protocol as tree topology. furthermore, The description of the LEACH Protocol can be seen in Figure 2. In Figure 2 there are 4 types of nodes i.e. Base station or edge router node, router node as cluster head, end node as sending sensor node and end node in the position of Low Power mode (LPM), Low Power Mode is a condition when the sensor node is in the Sleep mode position.

The purpose of sleep mode is to save energy on the Wireless sensor network (WSN) so that good energy efficiency is obtained. furthermore, The next architectural protocol besides LEACH is Hybrid Energy-Efficient Distributed (HEED) Clustering, HEED Protocol is almost the same as the LEACH Protocol, but in the HEED Protocol, each Cluster Head can communicate with each other, not like the LEACH Protocol that directly sends packet data to the Base station without any communication with other cluster heads. accordingly the HEED architecture protocol as a Mesh network. furthermore, HEED Protocol can be seen in Figure 3

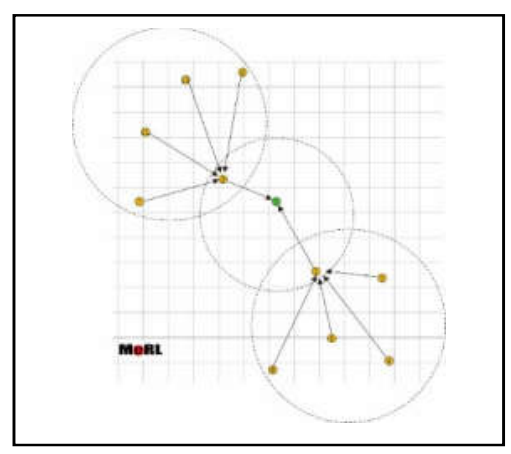

Fig. 2. LEACH Protocol 


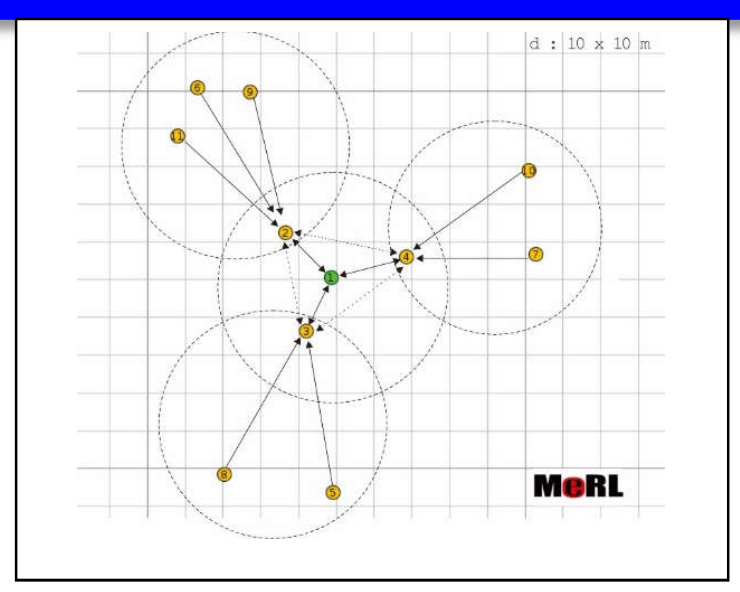

Fig. 3. HEED Protocol

Besides LEACH and HEED Protocols, is the Power-Efficient Gathering in Sensor Information System (PEGASIS) Protocols.

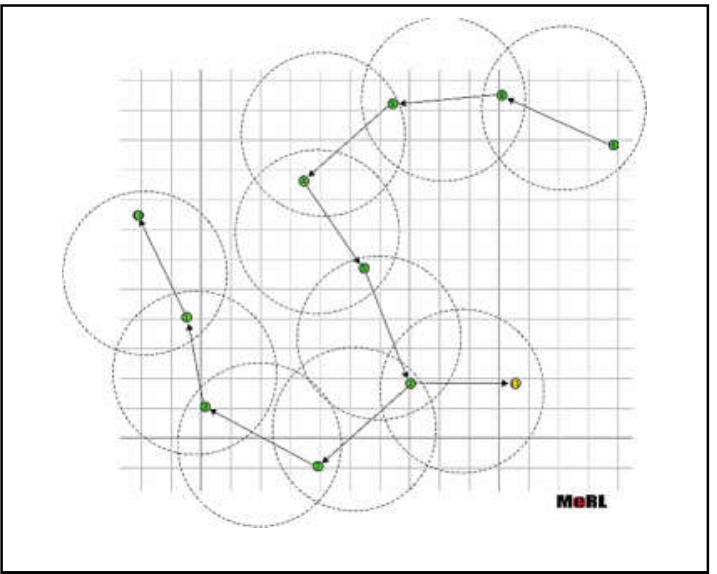

Fig. 4. PEGASIS Protocol

PEGASIS is a form of Wireless Sensor Network routing in the form of a chain that starts at the sensor node (start node) and ends with the last node (end node), while the Leader node is in a series of chain sequences on the HEED architecture. Therefore, the Leader node sends packet data to the Base Station. the modification on LEACH is LEACH-TLCH (Low Energy Adaptive Clustering Hierarchy with Two-Level Cluster Head) as shown in Figure 5.

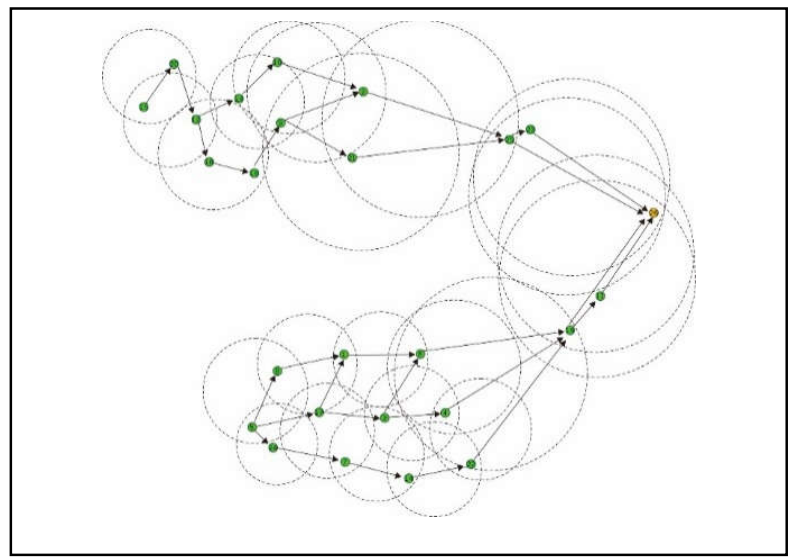

Fig. 5. LEACH-TLCH Protocol

Furthermore, Figure 6 shows the design of Internet of Things (IoT), packet data transmission is done with 3 protocols, namely LEACH, HEED or PEGASIS, therefore, the base station is the basis of gathering data packets from all nodes. Therefore, data in the base station is sent to the Internet 
Gateway, on the internet Gateway data is processed and stored in a database connected to the internet. In the previous study, Internet Gateway used was Raspberry Pi 3 Model B with a sample temperature sensor data, but in this research, a graphical User Interface (GUI) has not been created to represent data graph 2 temperature sensor LM35 [5]. In the research [6], it also discusses the energy efficiency using Fuzzy Logic, the input parameters used are Energy, BS Distance, AVG_Energy, Density and Compact and the Fuzzy method used is Mamdani Fuzzy Inferences System that produces output with the change parameter. In research [7] Energy efficiency uses the protocol algorithm and the one used is MN-LEACH. In this research, the condition of the sensor node changes place or mobility node, which will affect the power and energy consumption sensor node. furthermore, The development of protocol algorithm research was also conducted in research [8], in this study examining the performance of LEACH, HEED, and PEGASIS which was developed in this research by reviewing LEACH-TLCH which produced the largest Power Consumption on 100 nodes in this research.On the internet gateway, there are 2 processes, i.e. uplink, and downlink, communication from the edge router to the internet gateway is called an uplink, and downlink communication is the reverse communication from the internet gateway to the edge router. furthermore, the development of code scripts for receiving data from MySQL databases to devices with an internet connection such as JASON is needed at the final stage to dynamically support data display in Web browsers for all platforms or devices.

In Figure 6. Determination of energy efficiency ends at the Base station or Edge router so the conclusion is to produce energy efficiency must use a clustering system that is spread on each sensor node in a small number of clustering members and a large number of header nodes to send to edge router ie data sensor, therefore at this stage multiple Header nodes occur or a large number of Headers nodes. The development is in research [9] by integrating Wireless Sensor Networks (WSNs) into the Cyber-Physical System (CPSs) to improve performances, safety, reliability and usability of wireless automation systems.

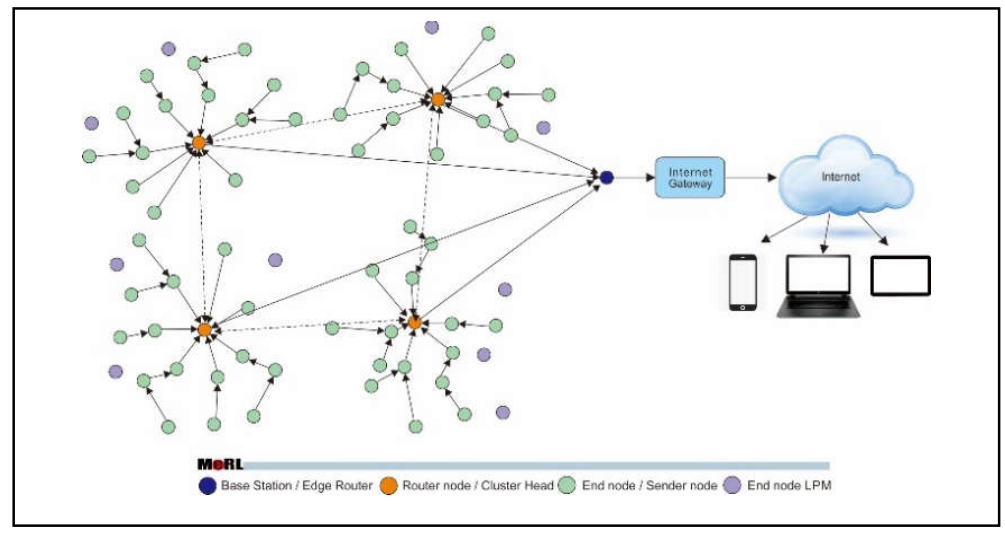

Fig. 6. IoT Desain with the clustering desain for energy efficiency

In addition to the above performances, an important factor is how EDs can manage power consumption, so an algorithm like in research [10] is needed, namely Adaptive Data Rate (ADR) Algorithm where, furthermore, each sensor nodes (EDs) in a static position sends sensor data during conditions steady state. Research [11] is an example of research applied to Search and Rescue (SAR) teams or natural disaster management teams, in this research Cellular Devices are used in sending sensor data, namely SIM900A.

\subsection{Energy Models}

An equation is needed to find energy efficiency by considering the position factor, the number of sensor nodes and cluster models when sending data $\mathrm{i}$ bits and distance $\mathrm{d}$.

Table 1. Variable of this Simulation Research

\begin{tabular}{ll}
\hline \multicolumn{1}{c}{ Variable } & \multicolumn{1}{c}{ Description } \\
\hline $\mathrm{E}_{\mathrm{Tx}}(\mathrm{i}, \mathrm{d})$ & Energy to transmit $\mathrm{i}$ bits at distance $\mathrm{d}$ \\
\hline $\mathrm{E}_{\mathrm{Rx}}(\mathrm{i})$ & Energy to received $\mathrm{i}$ bits \\
\hline $\mathrm{E}_{\text {elec }}$ & Energy to run transceiver circuitry \\
\hline
\end{tabular}




\begin{tabular}{ll}
\multicolumn{1}{c}{ Variable } & \multicolumn{1}{c}{ Description } \\
\hline$\varepsilon f s$ & The Free space (fs) energy loss \\
\hline$\varepsilon m p$ & The Multipath (mp) energy loss \\
\hline $\mathrm{n}_{\text {alive }}$ & Total number of alive sensors \\
\hline $\mathrm{E}_{\mathrm{r}}(\mathrm{q})$ & Residual energy of qth sensor \\
\hline $\mathrm{E}_{\mathrm{max}}$ & Initial maximum energy of a sensor node \\
\hline $\mathrm{d}^{2}{ }_{\mathrm{BS}}$ & Distance of the nearest node to the Base Station $(\mathrm{BS})$ \\
\hline $\mathrm{M}$ & Side-length of M x M deployment area \\
\hline $\mathrm{N}_{\mathrm{CH}}$ & Desired number of CHs \\
\hline $\mathrm{C}_{(\mathrm{c})}$ & $\mathrm{c}$ th cluster, where $\mathrm{c}: 1,2 \ldots . ., \mathrm{N}(\mathrm{CH})$ \\
\hline $\mathrm{NC}_{(\mathrm{c})}$ & Total numbers of members in cluster $\mathrm{C}_{(\mathrm{c})}$ \\
\hline $\mathrm{E}_{\mathrm{avg}} \mathrm{C}_{(\mathrm{c})}$ & Average node energy in cluster $\mathrm{C}_{(\mathrm{c})}$ \\
\hline $\mathrm{AND}_{\mathrm{Cen}} \mathrm{C}_{(\mathrm{c})}$ & Average node distance in cth cluster from its centroid \\
\hline $\mathrm{D}_{\mathrm{Cen}}(\mathrm{j})$ & Distance of jth member node from the cluster centroid \\
\hline $\mathrm{E}_{\mathrm{c} \text { omm }}$ & Energy Communication on Contiki-Cooja Simulator $(\mathrm{mJ})$ \\
\hline $\mathrm{E}_{\mathrm{cpu}}$ & Energy Consumed by CPU on Contiki-Cooja Simulator $(\mathrm{mJ})$ \\
\hline
\end{tabular}

Energy transmits bits at distance and Energy $\mathrm{i}$ bits expressed in equation 1 and Energy receive at $\mathrm{d}$ distance is stated in equation 2 [1] [3].

$$
\begin{aligned}
& E_{T x}(i, d)=i * E_{\text {elec }}+\left\{\begin{array}{l}
i * \varepsilon f s * d^{2} \forall d<d_{s}, \\
i * \varepsilon m p * d^{4} \forall d \geq d_{s},
\end{array}\right. \\
& E_{R x}(i, d)=i * E_{\text {elec }}
\end{aligned}
$$

Where $d_{s}$ is the distance $s$ at overcross condition can be seen on equation (3).

$$
d_{s}=\sqrt{\frac{\varepsilon f s}{\varepsilon m p}}
$$

d_s can also be determined by the following formula in equation 4 , in equation $4 . h_{t}$ and $h_{r}$ are antenna height, $\lambda$ is the wavelength with the formula $\lambda=\mathrm{c} / \mathrm{f}$, where $\mathrm{c}$ is the speed of light $3 \times 10^{8} \mathrm{~m} / \mathrm{s}, \mathrm{L}$ is the length of the direct line-of -sight (LOS) and the value $\mathrm{f}$ is frequency $(\mathrm{Hz})$.

$$
d_{s}=\frac{4 \pi \sqrt{L} h_{r} h_{t}}{\lambda}
$$

Viewed from the sensor node that wants to be a Cluster Head $(\mathrm{CH})$ can be formulated from the sensor Node approach by looking at various factors such as $\varepsilon f s, \varepsilon m p, n_{\text {alive }}$ dan $\mathrm{d}^{2}{ }_{\text {BS }}$ stated in equation (5).

$$
N_{C H}=\frac{M}{d^{2} B S} \sqrt{\frac{\varepsilon f s}{\varepsilon m p}} \sqrt{\frac{n_{\text {alive }}}{2 \pi}}
$$

Total dari seluruh energy yang dibutuhkan oleh sensor node meliputi energy CPU, energy to transmit $\left(E_{T x}(i, d)\right)$, energy to receiver $E_{R x}(i, d)$, dan dapat dinyatakan dengan energy average, seperti pada equation (6).

$$
E_{\text {avg }} C_{(c)}=\frac{\sum_{j=1}^{N} E(i)_{r}}{N} \forall j \in C_{(c)},
$$

Energy Transmitter $\mathrm{E}_{\mathrm{Tx}}$ and receiver $\mathrm{E}_{\mathrm{Rx}}$ in the process of sending data (bit packet) is affected by several parameters, i.e. distance (d), $\mathrm{E}_{\text {elec }}, \varepsilon_{\mathrm{amp}}$, and i bits. 


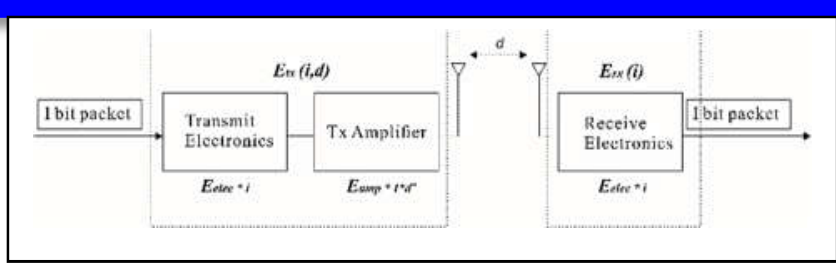

Fig. 7. Energy Dissipation WSN model

On Figure 7, Distance (d) affects signal strength at the Receiver (Rx). The receiver signal strength is expressed by the parameter $\mathrm{P}_{-} \mathrm{r}(\mathrm{mW})$ or $\mathrm{dB}$. In Equation 7, the size of the Power receiver is determined by the Power Transmitter, Gain on the transmitter (Gt) and Receiver Gain (Gr) and L is the length of the direct Line-of-sight (LOS). ds (cross over) and $\mathrm{d}<\mathrm{ds}$ (cross over).

$$
P_{r}= \begin{cases}\frac{\frac{G_{t} G_{r} \lambda^{2}}{(4 \pi d)^{2} l}}{\frac{P_{t} G_{t} G_{r} h_{t}^{2} h_{r}^{2}}{d^{4}}} \text { if } d \geq d_{s},\end{cases}
$$

Determining the Average power result from the simulation using the Contiki cooja simulator is Avg Power Total $=$ LPM Power Node + Listen to Power $(\mathrm{Rx})+$ Transmit Power $(\mathrm{Tx})+$ CPU Power [5]. In simulation software, there are 2 important parameters namely Energy Communication $(\mathrm{mJ})$ and Energy Consumed by CPU. 4 The components mentioned in the total power formula are TX (ENERGEST TYPE_TRANSMIT),

$$
\mathrm{RX}
$$

(ENERGEST TYPE LISTEN), CPU(ENERGEST_TYPPE_CPU) and cpu_idle (ENERGEST_TYPE_LPM), and energy Communication can be represented by equation 8

$$
E_{c}(m J)=\frac{(T x * 17.7 m A)+(R x * 20 m A)}{32768} * 3 V
$$

Furthermore, Energy Consumed by CPU can be represented by equation 9 .

$$
E_{c p u}(m J)=\frac{(T c p u)}{32768} * 1.8 m A * 3 V
$$

$32768 \mathrm{~Hz}$ or $32.768 \mathrm{kHz}$ adalah Frequency of MSP430F247 Microcontroller on Figure 8. If the active node condition the node specify is 32iuA@3v/1 MHz or 1x106 Hz and Low Power mode is 1uA@3V/32768 Hz.

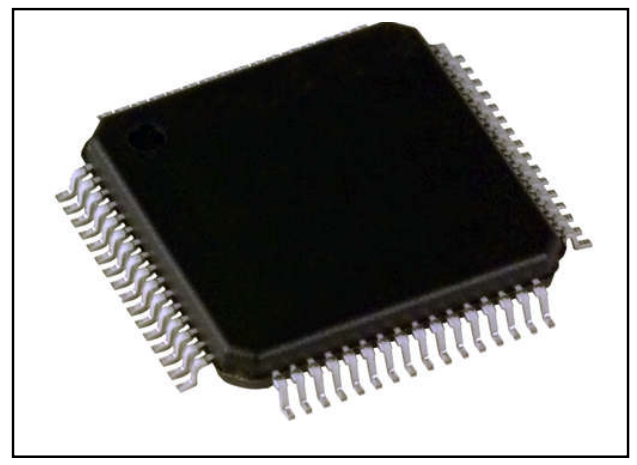

Fig. 8. IC of MSP430F 247

The technology used to support the fulfillment of a Wireless Sensor Network that is flexible, dynamic and supports the durability of sensor nodes is fundamental. In research [10] developing RFID devices on sensor network networks, this would prove that the development of sensor node devices is better, with energy efficiency and the fulfillment of reliable communication systems. therefore, Talking about energy efficiency is inseparable from the network architecture that was built, in this case closely related to distance and the protocol method used, in research [11] using the Multi-hop-DISCPLN method to maintain the stability of the network. Complex wireless sensor networks make complexity in the system settings between the control plane and the data plane so that in research [12] researched Software-defined networks (SDN) to sort out these factors to produce a reliable 6LoWPAN network. 


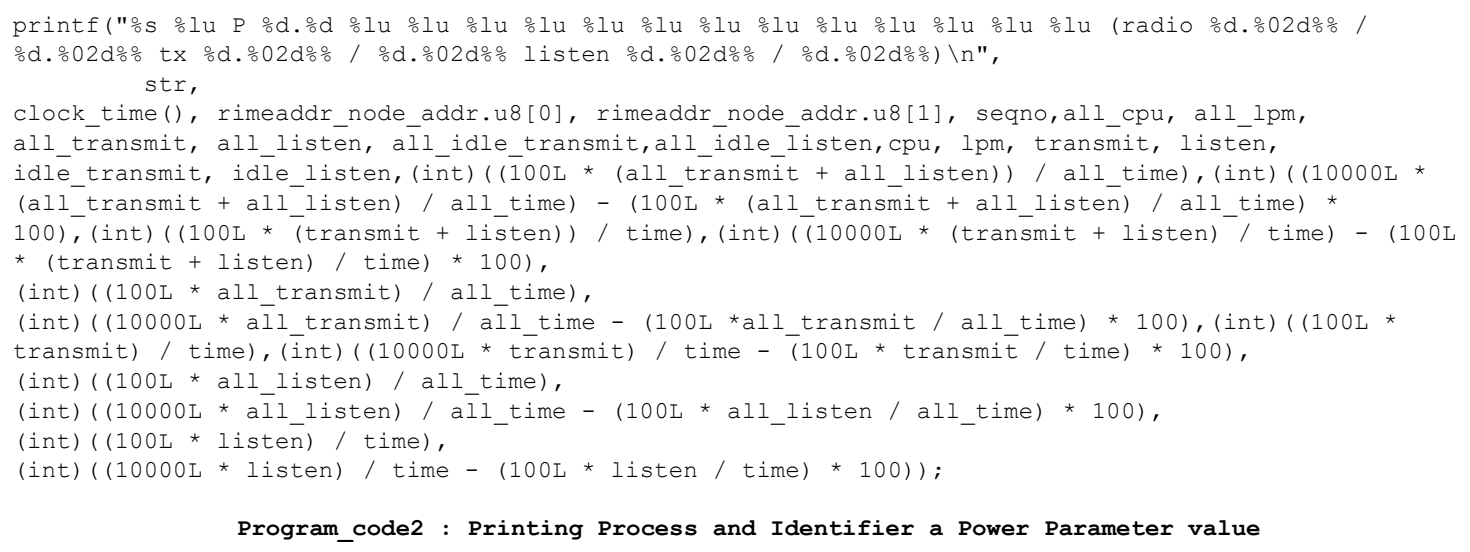

\section{Method}

\subsection{Flowchart System}

This research is depicted in the flowchart in Figure 14. Accordingly, in this research, The software used is open sources simulation software which is Contiki-cooja based on the Ubuntu version of the Linux Operating System. In this software, IEEE 802.15.4 radio protocol is used with the specifications of Low Power Personal Area Network, namely the mote sensor node. furthermore, There are 4 algorithm protocols, i.e. HEED, LEACH, LEACH-TLCH and PEGASIS, after the algorithm selection process ends, the result is the average total power consumption, a comparison between all routing algorithms with the magnitude of power consumption is generated from the average value of all sensor node parameters i.e. LPM Power node, Listen Power (Rx), Transmit Power (Tx) and CPU Power [5].

Furthermore, the WSN LEACH protocol architecture is depicted in Figure 10, this already represents the number of other nodes, i.e. 20 nodes and 100 nodes. Furthermore, Figure 11 is an example of a HEED Protocol that is run in simulation software and represents 50 and 100 other nodes. Furthermore, Figure 12 is an example of a LEACH-TLCH algorithm protocol with 50 nodes representing 20 and 100 other nodes. Furthermore, Figure 13 is the PEGASIS Algorithm Protocol with 100 nodes representing 20 and 50 node PEGASIS Figures. Several other studies have examined the best RPL protocol that can be done for example making SIGMA-ETX in research [13] to obtain parameters with optimal results e.g. network latency, packet delivery, ratio, lifetime and power consumption.

\subsection{Architecture WSN on Simulation tool}

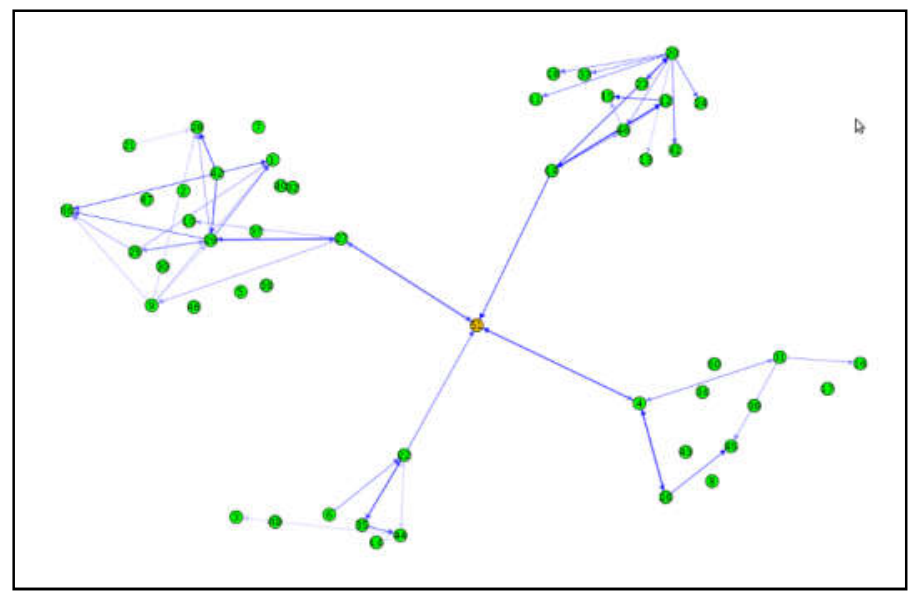

Fig. 10. 50 sensor node on LEACH Algorithm protocol 


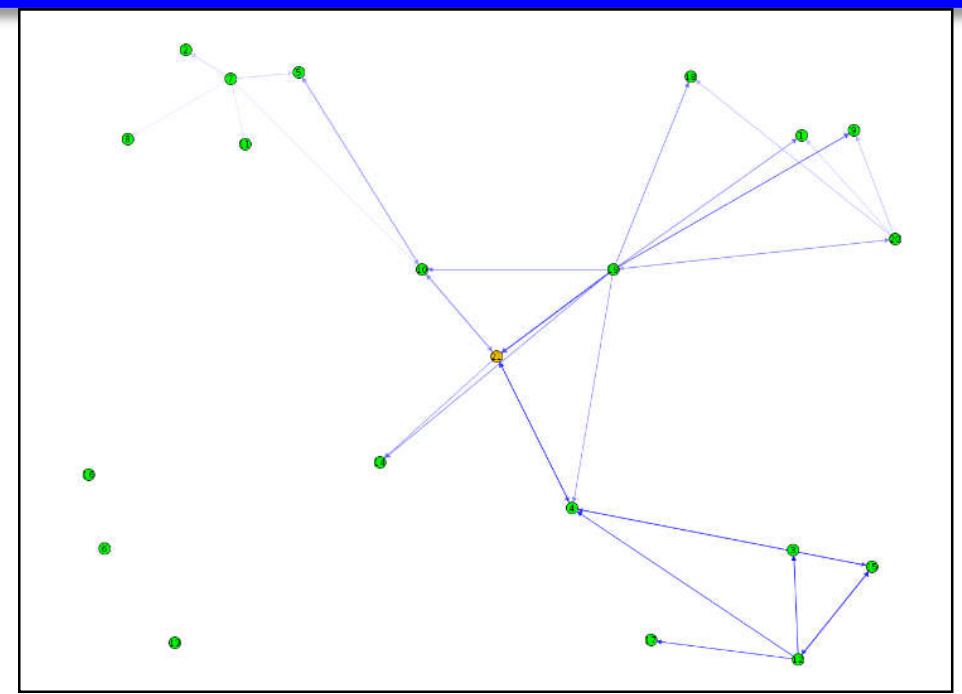

Fig. 11. 20 sensor node on HEED Algorithm protocol

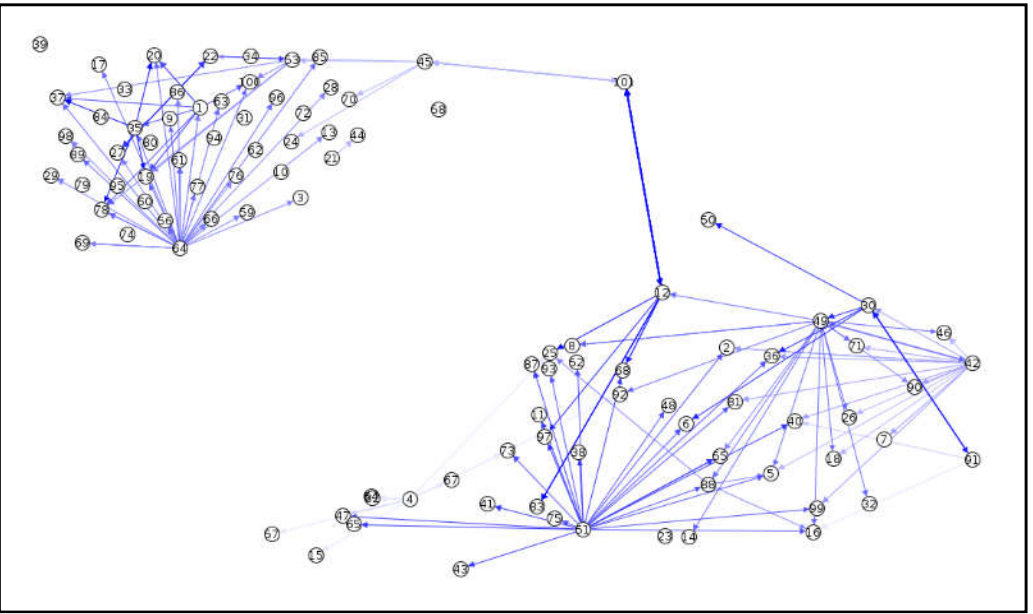

Fig. 12. 50 sensor node on LEACH-TLCH Algorithm protocol

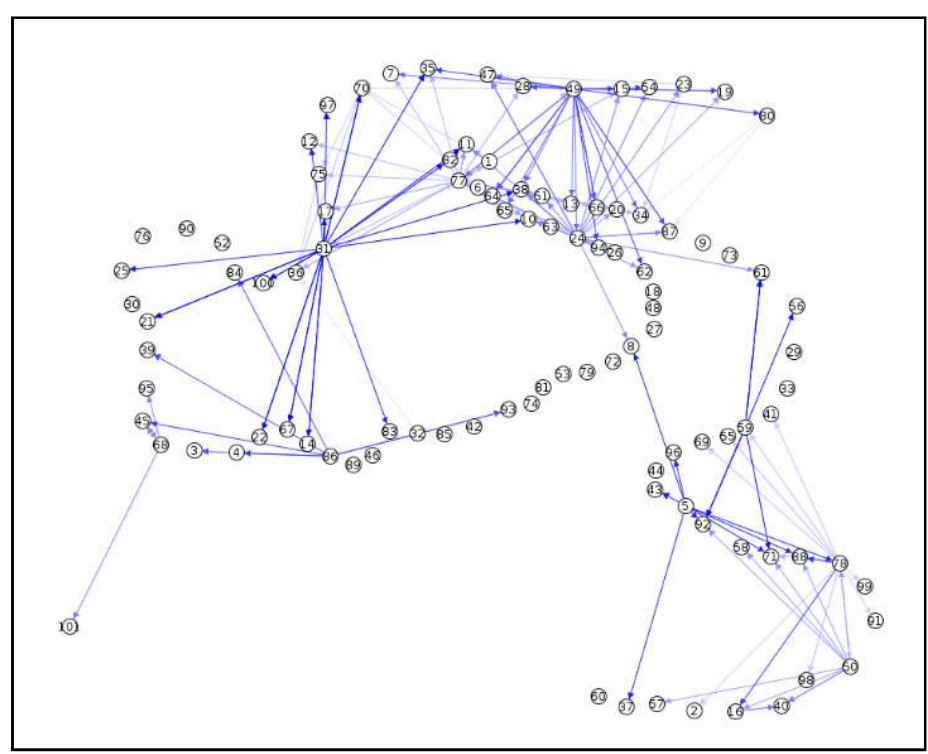

Fig. 13. 100 sensor node on PEGASIS Algorithm protocol 


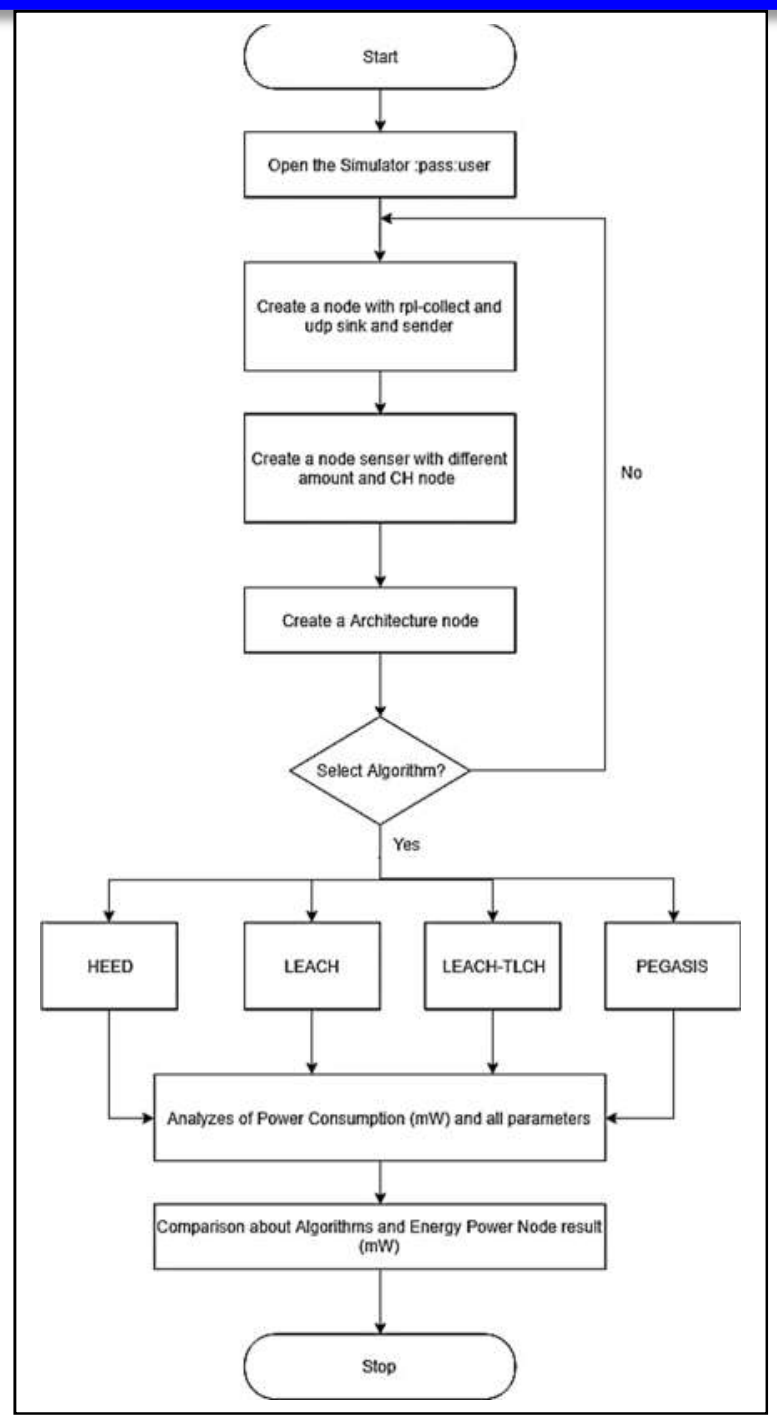

Fig. 14. The Flowchart of Simulation Process on this research

And the time of testing in Figure 10, Figure 11, Figure 12 and Figure 13 is representative of the whole picture that was tested in this research. Namely with 4 LEACH, LEACH-TLCH, HEED, and PEGASIS protocol algorithms and with the same number of nodes, 20, 50 and 100 nodes, which were carried out at the same time, 5 minutes simulation time. The tool or software used is Contiki cooja 2.7. This software is used as a search for Low Power mode with an approach to Low Power and Lossy Network with the sensor node devices that have been provided, according to Figure 7. IC of MSP430F247.

\section{Results and Discussion}

\subsection{The result of comparison of Algorithm type Protocols with the Different number of nodes}

Figure 15 is a comparison of 4 algorithm protocol methods namely HEED, LEACH, LEACHTLCH and PEGASIS using 21 sensor nodes, consisting of 20 sensor nodes for the sender and 1 sensor node as a sink. From the results of 20 sensor nodes, the lowest total power (mW) is 1.21 $\mathrm{mW}$, LEACH followed by HEED with $1,235 \mathrm{~mW}$, furthermore, LEACH-TLCH with 1,266 $\mathrm{mW}$ and architecture WSN Protocol method with the largest Power Consumption is PEGASIS with $1,361 \mathrm{~mW}$, this concludes that PEGASIS is not suitable for building WSN network architectures due to Long Life parameters that are still inferior to other network architects. It is concluded that best by the principle of RPL (Low Power and Lossy Network) is the LEACH Protocol.

furthermore, In Figure 16. Result of comparison type protocols with 50 sensor nodes are shown and the highest to lowest Power Consumption $(\mathrm{mW})$ calculations are sorted as follows: LEACH- 
TLCH (1,952 mW), PEGASIS (1,908 mW), LEACH (1,604 mW) and HEED (1,558 mW). different value of HEED Algorithm and LEACH on 50 nodes is $0.046 \mathrm{~mW}$, this is not significantly influential, the difference is also low to verify a LEACH produce the lowest power consumption. Furthermore, the Comparison of Algorithm type with 100 nodes, show in Figure 17 and it is produced that LEACH-TLCH has the highest total Power Consumption, which is $4,851 \mathrm{~mW}$ followed by PEGASIS $4.31 \mathrm{~mW}$, HEED $2689 \mathrm{~mW}$ and the lowest Total Power Consumption is LEACH which is $2,038 \mathrm{~mW}$ Figure 18 shows the overall this method. table II shows the overall results to understand by easier.

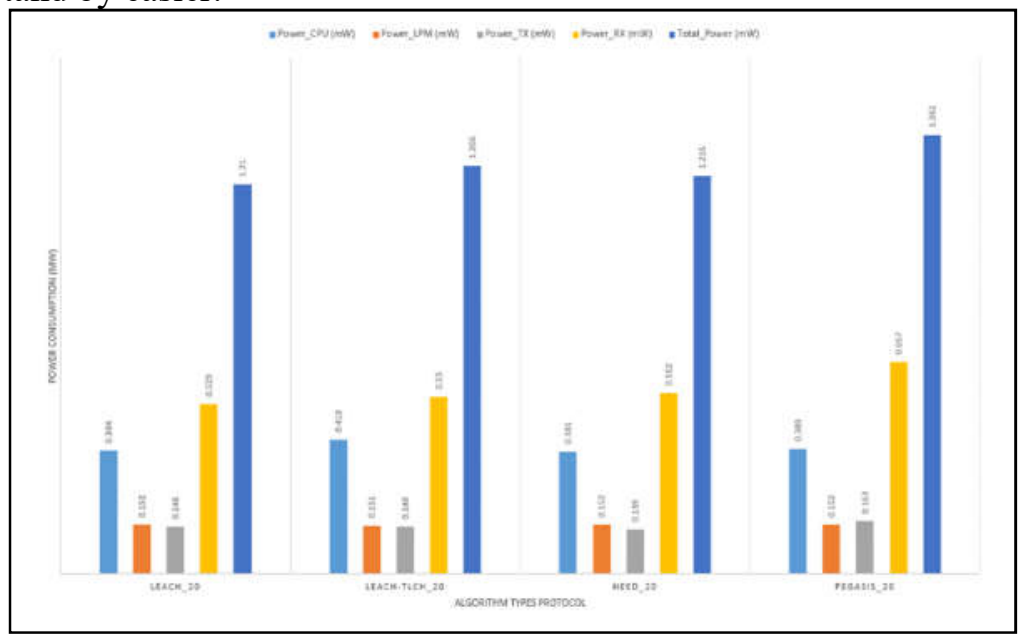

Fig. 15. The result of comparison of Algorithm type Protocols with the number of 20 nodes

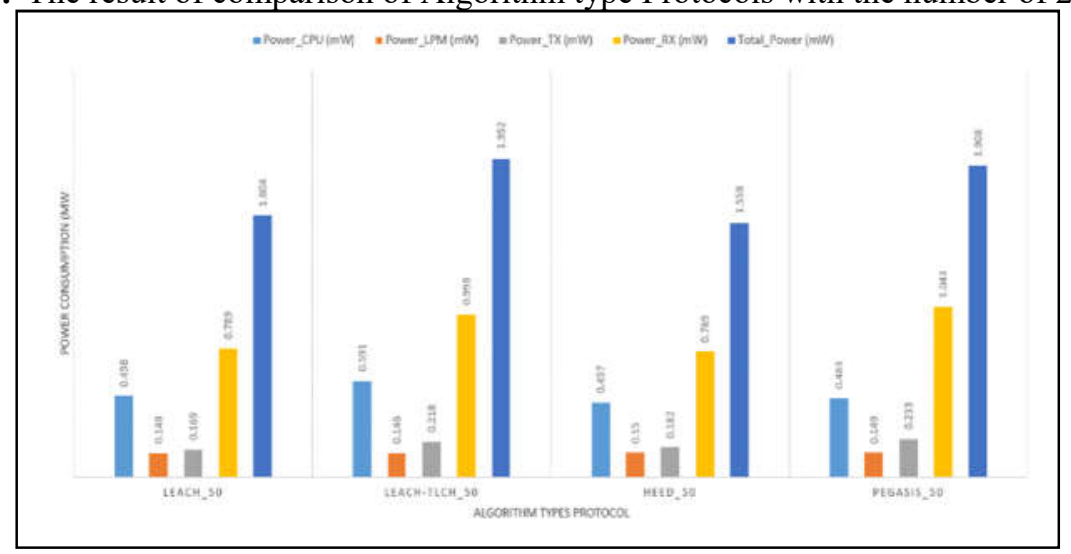

Fig. 16. The result of comparison of Algorithm type Protocols with the number of 50 nodes

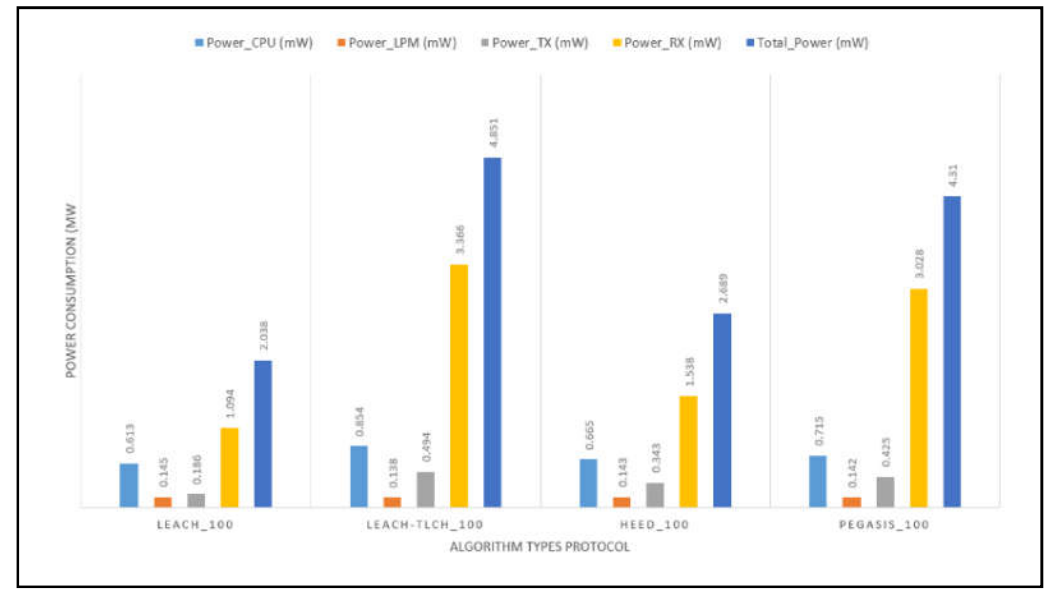

Fig. 17. The result of comparison of Algorithm type Protocols with the number of 100 nodes 


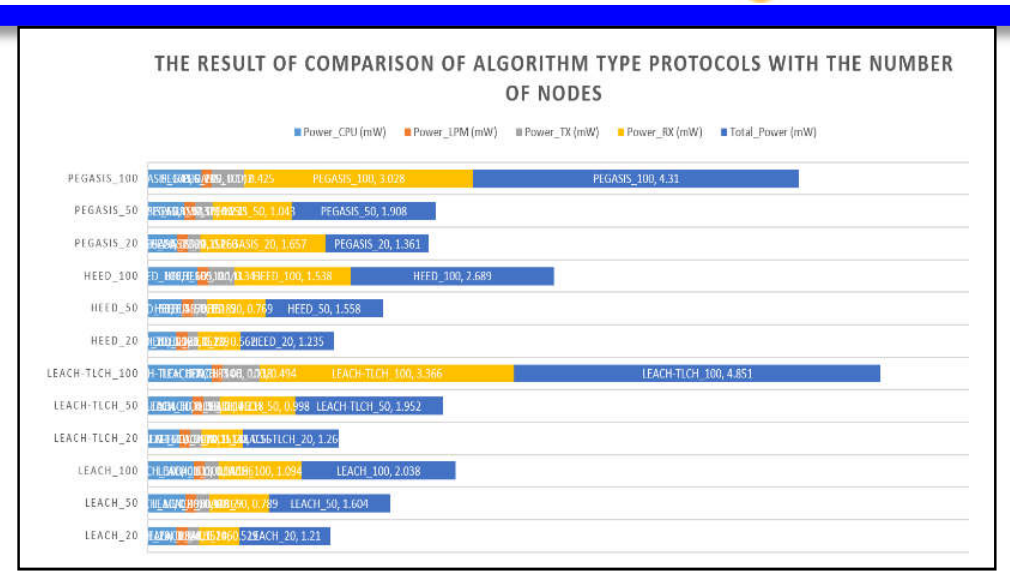

Fig. 18. The result of comparison of Algorithm type Protocols

Table 2. Comparison of Algorithm Protocol Types and several nodes

\begin{tabular}{lccccc}
\hline \multicolumn{1}{c}{ Node_Identifier } & $\begin{array}{c}\text { Power_CPU} \\
(\boldsymbol{m} \boldsymbol{W})\end{array}$ & $\begin{array}{c}\text { Power_LPM } \\
(\boldsymbol{m} \boldsymbol{W})\end{array}$ & $\begin{array}{c}\text { Power_TX} \\
(\boldsymbol{m} \boldsymbol{W})\end{array}$ & $\begin{array}{c}\text { Power_RX} \\
(\boldsymbol{m} \boldsymbol{W})\end{array}$ & $\begin{array}{c}\text { Total_Power } \\
(\mathbf{m} \boldsymbol{W})\end{array}$ \\
\hline LEACH_20 & 0.384 & 0.152 & 0.146 & 0.529 & 1.21 \\
\hline LEACH-TLCH_20 & 0.418 & 0.151 & 0.148 & 0.55 & 1.266 \\
\hline HEED_20 & 0.381 & 0.152 & 0.139 & 0.562 & 1.235 \\
\hline PEGASIS_20 & 0.389 & 0.152 & 0.163 & 1.657 & 1.361 \\
\hline LEACH_50 & 0.498 & 0.148 & 0.169 & 0.789 & 1.604 \\
\hline LEACH-TLCH_50 & 0.591 & 0.146 & 0.218 & 0.998 & 1.952 \\
\hline HEED_50 & 0.457 & 0.15 & 0.182 & 0.769 & 1.558 \\
\hline PEGASIS_50 & 0.483 & 0.149 & 0.233 & 1.043 & 1.908 \\
\hline LEACH_100 & 0.613 & 0.145 & 0.186 & 1.094 & 2.038 \\
\hline LEACH-TLCH_100 & 0.854 & 0.138 & 0.494 & 3.366 & 4.851 \\
\hline HEED_100 & 0.665 & 0.143 & 0.343 & 1.538 & 2.689 \\
\hline PEGASIS_100 & 0.715 & 0.142 & 0.425 & 3.028 & 4.31 \\
\hline
\end{tabular}

\section{Conclusion}

The number of nodes determines the Power Consumption $(\mathrm{mW})$ needed in the process of sending sensor data. accordingly, From experiments conducted in this research by comparing 4 protocol methods with different number of sensor nodes, the LEACH-TLCH protocol algorithm method was produced with the largest total power of $4,851 \mathrm{~mW}$, followed by PEGASIS with the number of sensor nodes 100 with a total of $4.31 \mathrm{~mW}$, followed by, then HEED with a total Power of $2,689 \mathrm{~mW}$ and the most in need of low power is LEACH with a total Power of 2,038 mW. At a smaller number of nodes, which are 20 nodes, LEACH needs the lowest power, which is $1.21 \mathrm{~mW}$, while the highest is PEGASIS with $1,361 \mathrm{~mW}$. furthermore, At the number of 50 nodes, the lowest is HEED, but the difference is $0.046 \mathrm{~mW}$ with LEACH and this result is not significant. In broad outline, LEACH excels in the lowest Power Consumption to build a Wireless Sensor Network. can use topology or LEACH protocol method. 


\section{References}

[1] P. D. P. Adi and A. Kitagawa, "ZigBee Radio Frequency (RF) Performance on Raspberry Pi 3 for Internet of Things (IoT) based Blood Pressure Sensors Monitoring," Int. J. Adv. Comput. Sci. Appl., vol. 10 , no. $5,2019$.

[2] P. D. P. Adi and A. Kitagawa, "Quality of Service and Power Consumption Optimization on the IEEE 802.15. 4 Pulse Sensor Node based on Internet of Things," Int. J. Adv. Comput. Sci. Appl., vol. 10, no. $5,2019$.

[3] L. Sitanayah, C. J. Sreenan, and S. Fedor, "A Cooja-based tool for coverage and lifetime evaluation in an in-building sensor network," J. Sens. Actuator Networks, vol. 5, no. 1, pp. 1-22, 2016.

[4] R. Lajara, J. Pelegri-Sebastia, and J. J. Perez-Solano, "Power Consumption Analysis of Operating Systems for Wireless Sensor Networks,” Sensors (Basel)., vol. 10, pp. 5809-5826, Jun. 2010.

[5] P. Dani Prasetyo Adi and A. Kitagawa, "Performance Evaluation WPAN of RN-42 Bluetooth based (802.15.1) for Sending the Multi-Sensor LM35 Data Temperature and RaspBerry Pi 3 Model B for the Database and Internet Gateway," Int. J. Adv. Comput. Sci. Appl., vol. 9, Jan. 2018.

[6] A. Hamzah, M. Shurman, O. Al-Jarrah, and E. Taqieddin, "Energy-efficient fuzzy-logic-based clustering technique for hierarchical routing protocols in wireless sensor networks," Sensors, vol. 19, no. 3, p. 561, 2019.

[7] M. Z. S. Hadi, A. Pratiarso, and H. Uehara, "An energy efficiency mobile clustering system for wireless sensor networks," management, vol. 1, no. 3, p. 4, 2006.

[8] G. K. Nigam and C. Dabas, "Performance Analysis of Heed Over Leach and Pegasis in Wireless Sensor Networks," in The World Congress on Engineering and Computer Science, 2015, pp. 259266.

[9] F. Ferracuti, A. Freddi, A. Monteriù, and M. Prist, "An integrated simulation module for cyberphysical automation systems," Sensors, vol. 16, no. 5, p. 645, 2016.

[10] P. D. P. Adi and A. Kitagawa, "Performance Evaluation of E32 Long Range Radio Frequency 915 MHz based on Internet of Things and Micro Sensors Data," Perform. Eval., vol. 10, no. 11, 2019.

[11] P. D. P. Adi and R. Arifuddin, "Design Of Tsunami Detector Based Sort Message Service Using Arduino and SIM900A to GSM/GPRS Module," JEEMECS (Journal Electr. Eng. Mechatron. Comput. Sci., vol. 1, no. 1, pp. 1-4, 2018.

[12] M. L. F. Miguel, E. Jamhour, M. E. Pellenz, and M. C. Penna, "SDN architecture for 6LoWPAN wireless sensor networks," Sensors, vol. 18, no. 11, p. 3738, 2018.

[13] P. Sanmartin, A. Rojas, L. Fernandez, K. Avila, D. Jabba, and S. Valle, "Sigma routing metric for RPL protocol," Sensors, vol. 18, no. 4, p. 1277, 2018. 
This page intentionally left blank 